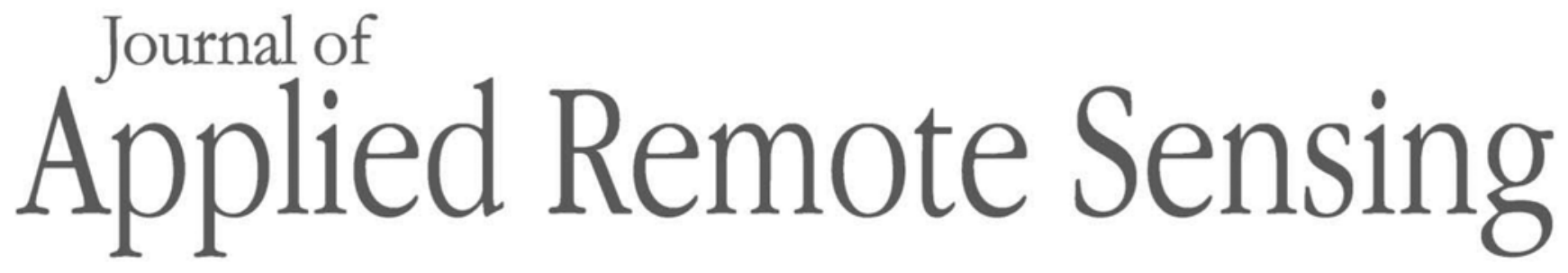

RemoteSensing.SPIEDigitalLibrary.org

\title{
Differing ecosystem responses of vegetation cover to extreme drought on the Big Sur coast of California
}

\author{
Christopher Potter
}




\title{
Differing ecosystem responses of vegetation cover to extreme drought on the Big Sur coast of California
}

\author{
Christopher Potter* \\ NASA Ames Research Center, Moffett Field, California, United States
}

\begin{abstract}
Impacts of the extreme 2013 to 2014 drought on vegetation canopy cover in the Big Sur region of central coastal California were assessed using a combination of satellite image analysis and in situ measurements of soil moisture. Landsat and moderate resolution imaging spectroradiometer satellite images were analyzed and compared across six ecosystems representative of the predominant vegetation types of the region at the U. S. Forest Service's Brazil Ranch study site. Results showed that differing spatial densities of woody plants among these ecosystems corresponded to the observed changes in the normalized difference vegetation index (NDVI) over the period of 2010 to 2016, with the herbaceous-dominated coastal terrace, open shrub, and ridge-top grassland ecosystems declining $30 \%$ in greenness during the extreme drought period of 2012 to 2014. Landsat images from the month of peak annual NDVI confirmed this as a statistically significant difference in the loss of green cover in open shrub and grassland ecosystems during the 2012 to 2014 drought, compared to the closed shrubland and redwooddominated ecosystems that were relatively unaffected at the study site. ( The Authors. Published by SPIE under a Creative Commons Attribution 3.0 Unported License. Distribution or reproduction of this work in whole or in part requires full attribution of the original publication, including its DOI. [DOI: 10 .1117/1.JRS.12.026031]
\end{abstract}

Keywords: drought; Pacific coast; California; forest; coast redwood; shrubland; grassland.

Paper 180148 received Feb. 20, 2018; accepted for publication Jun. 5, 2018; published online Jun. 25, 2018.

\section{Introduction}

The Pacific coastal region near Big Sur (Monterey County, California) is subjected to frequent droughts and wildfires, ${ }^{1}$ extreme winter storm events, ${ }^{2}$ and human development impacts, together affecting wildlife populations, native plant communities, riparian zones, and water quality. The numerous unique microclimates of Big Sur make it an important region in western United States to monitor impacts on natural biodiversity, ${ }^{3}$ including many endemic rare and endangered species, such as the wild orchid Piperia yadonii, the Santa Lucia fir (Abies bracteata), California condor (Gymnogyps californianus), California southern sea otter (Enhydra lutris nereis), and the southern-most habitat of the coast redwood (Sequoia sempervirens). The Pacific coastal redwood ecoregion has been identified by the World Wildlife Fund as being in the highest conservation priority class among ecoregions in the United States, based on biological uniqueness, conservation status, and impending threats. ${ }^{4}$

Calendar year 2013 was the driest on record in California, with a total of just $30 \%$ of average statewide precipitation. ${ }^{5}$ The previous statewide record low was $56 \%$ of average precipitation in 1976. This extreme lack of rainfall during 2013 and 2014 wet seasons created an unprecedented level of stress on natural ecosystems and agricultural production systems throughout the central regions of state, ${ }^{6}$ where there remains a pressing need to develop assessment methods for mitigating local drought impacts and future risks.

The main purpose of this study was to assess the impacts of the extreme 2013 to 2014 drought on ecosystem plant cover of the Big Sur region using a combination of satellite image analysis and in situ measurements of soil moisture across six ecosystems representative of the predominant vegetation types of the region. The study site for this analysis is arguably

*Address all correspondence to: Christopher Potter, E-mail: chris.potter@nasa.gov 
located at the nexus of modern climate change geography in the western United States. This 490-ha property overlooking the Big Sur coast is home to all the predominant ecosystems of the region, including coastal grassland terrace, ridge-top grassland and coast redwood stands, open and closed shrublands, and creek-side coast redwoods. The close proximity of these diverse vegetation communities to one another on the study site, all within ready access to paved roads, makes the opportunity for comparison of regional drought impacts on vegetation cover uniquely valuable for long-term ecosystem studies.

\section{Study Site Description}

This study was located at the Brazil Ranch (center coordinates: latitude $36.36^{\circ} \mathrm{N}$ and longitude $121.89^{\circ} \mathrm{W}$ ) in the northern Los Padres National Forest (LPNF) of Monterey County near Big Sur, California (Fig. 1). This protected public property is named after the pioneer family that worked to establish the land as a farm, ranch, as well as a dairy operation in the early 20th century. Today, the property serves as a primary research site for the U. S. Forest Service LPNF, to monitor and manage vegetation, wildlife, water quality, and sensitive coastal habitats.

The Big Sur region is generally delineated by $140 \mathrm{~km}$ (90 miles) of coastline from the Carmel River in northern Monterey County, south to the San Carpoforo Creek in San Luis Obispo County, and extends about $30 \mathrm{~km}$ inland to the eastern foothills of the Santa Lucia Mountains. The terrain is rugged and undulating, with the steepest elevation gradients on the Pacific U. S. coast, ${ }^{7}$ ranging (over just several $\mathrm{km}$ inland) from sea level up to $1570-\mathrm{m}$ elevation.

The region has Mediterranean climate of warm, dry summers and cool, wet winters, with localized summer fog near the coast. ${ }^{2,8}$ The majority of annual precipitation falls in the winter (November to March), annually varying from 40 to $150 \mathrm{~cm}$ throughout the range, with most falling on the higher mountains in the northern extreme. ${ }^{1}$ During the summer, low clouds are frequently observed along the coast. ${ }^{9}$ Summer fog is common below about $600 \mathrm{~m}(2000 \mathrm{ft})$ elevation. ${ }^{2}$ Mean annual temperature ranges from $10^{\circ} \mathrm{C}$ to $15^{\circ} \mathrm{C}$ from canyon bottom to
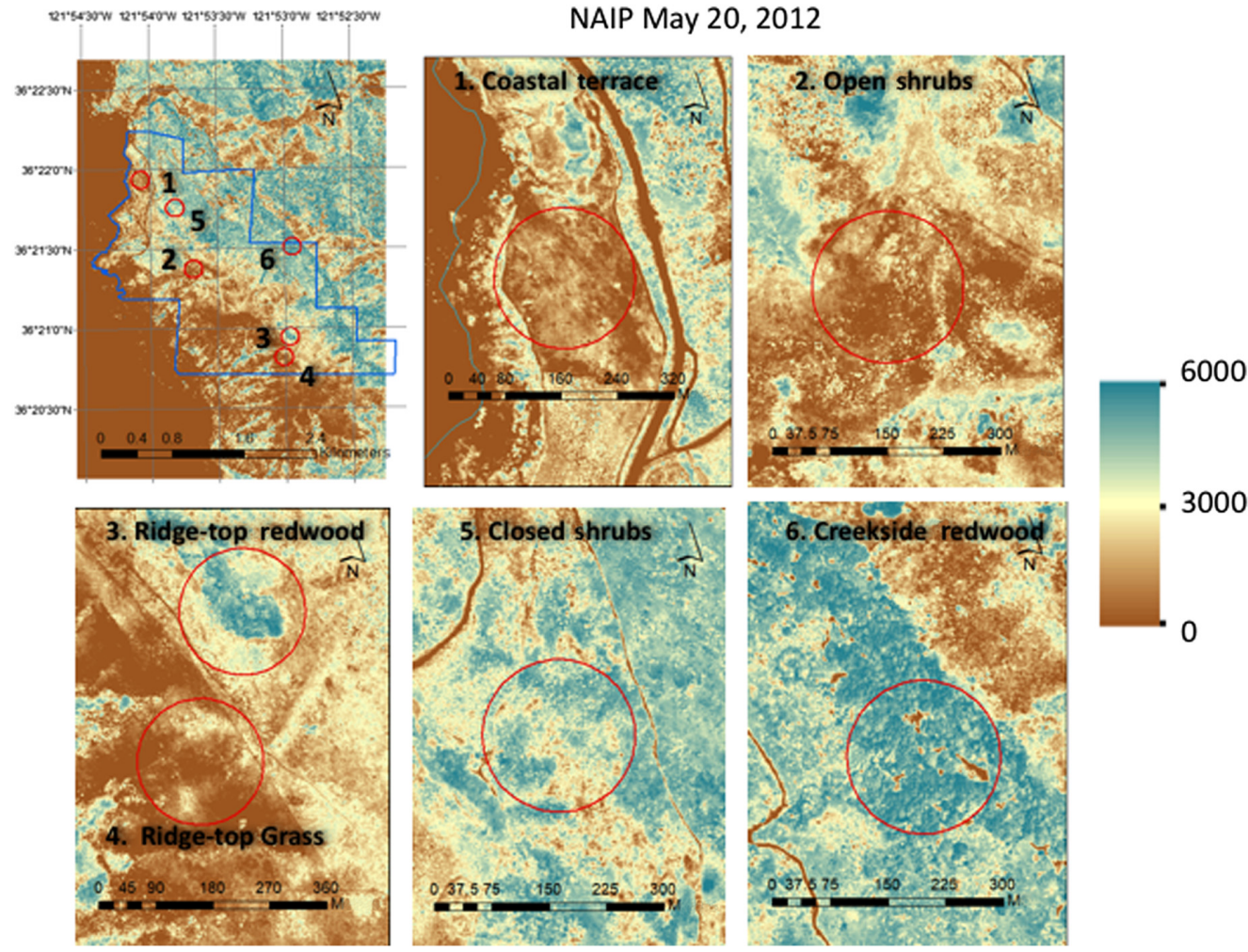

Fig. 1 NAIP aerial image from May 2012 of 1-m resolution NDVI for the Brazil Ranch study area (delineated by the blue line), with six 100-m radius ecosystem boundaries (red circles). 
ridge top, respectively. ${ }^{1}$ Diurnal heating and cooling of ecological habitats along the Big Sur coast and higher into the Santa Lucia range involves a complex series of elevation gradients and topographic variations.

South-facing slopes on Brazil Ranch share a relatively equal distribution of coyote brush (Baccharis pilularis) and California coffeeberry (Rhamnus californica) along with some California sagebrush (Artemisia californica). ${ }^{3}$ The nearly vertical slopes of coastal grassland and shrubland vegetation on ocean-facing bluffs starting just above sea level give way to mixed hardwood (predominantly oaks) and pine (Pinus ponderosa) forests at around 100-m elevation, which in turn transition to Coulter pine (Pinus coulteri) woodlands at around $850 \mathrm{~m} \mathrm{(3000 \textrm {ft } )}$ elevation. ${ }^{10}$ Along the riparian canyon bottoms and on the moist lower parts of north-facing slopes below about $60-\mathrm{m}$ elevation, coast redwood stands are able to grow. ${ }^{11}$ Logging removed the majority of mature redwood stands in California over the past 200 years ${ }^{12}$ and has rendered most present stands as secondary growth, aged between 100 and 150 years. ${ }^{11,13}$

Plant growth on the Big Sur coast can be highly variable from year-to-year and is generally limited by declines of soil moisture in the summer and by cool temperatures in the winter. ${ }^{1}$ The annual production pattern for coastal plants is rapid growth in the late fall (November) after the first rains have returned, slow winter growth (December to February), and rapid growth again in spring (March to May). ${ }^{14}$

\section{Methods}

\subsection{Climate Data}

Monthly climate summaries from 2000 to 2017 were obtained from the Western Regional Climate Center California Climate Tracker ${ }^{15}$ data porta $^{16}$ for the Big Sur State Park (BSP, NWS ID\# 040790; elevation $320 \mathrm{~m}$ ); station BSP represents the longest, complete rainfall record on the Monterey County coast south of Carmel, dating back to 1950 for rainfall measurements. The station is situated $3.5 \mathrm{~km}$ due east from the ocean coastline and $14 \mathrm{~km}$ from the Brazil Ranch.

A Campbell weather station equipped with a CR800 data logger, a 03001 R. M. Young Wind Sentry Set, and an HMP45C temperature and relative humidity probe was installed in open ocean-facing grassland at the Brazil Ranch in 2007. The ongoing hourly meteorological data collection included air temperature, humidity, wind speed and direction, and solar irradiance. ${ }^{17}$

\subsection{Soil Moisture Measurements}

Soil moisture probes were placed in ridge-top grassland and open shrubland ecosystems at the Brazil Ranch at depths of 10 and $30 \mathrm{~cm}$ in the soil profiles. As described by Potter, ${ }^{17}$ volumetric water content (VWC) was monitored on an hourly interval using EC-5 frequency domain probes (Decagon Devices Inc.).

\subsection{Landsat and Moderate Resolution Imaging Spectroradiometer Satellite Image Data}

Near cloud-free imagery from the Landsat sensor was selected from the United States Geological Survey (USGS) Earth Explorer data portal (available online) ${ }^{18}$ Landsat scenes from path/row 43/35 were acquired between April 1 and May 1 each year, around the peak of the Pacific coastal growing season. ${ }^{17}$ All images used in this study were geometrically registered (UTM zone 10) using terrain correction algorithms (level-1T) applied by the USGS EROS Data Center. Due to sensor malfunction, Landsat imagery was not available for the year 2012.

For the Landsat 5 Thematic Mapper (TM) images acquired in 2010 and 2011, 30-m resolution surface reflectance data were generated from the Landsat Ecosystem Disturbance Adaptive Processing System. ${ }^{19}$ Moderate resolution imaging spectroradiometer (MODIS) atmospheric correction routines were applied to level-1 TM data products. Water vapor, ozone, geopotential height, aerosol optical thickness, and digital elevation are input with Landsat data to 
the second simulation of a satellite signal in the solar spectrum (6S) radiative transfer models to generate top of atmosphere reflectance, surface reflectance, brightness temperature, and masks for clouds, cloud shadows, adjacent clouds, land, snow, ice, and water. Landsat 8 (after 2012) surface reflectance products were generated from the L8SR algorithm, ${ }^{20}$ a method that uses the scene center for the sun angle calculation and then hard codes the view zenith angle to 0 . The solar zenith and view zenith angles are used for calculations as part of the atmospheric correction.

The normalized difference vegetation index (NDVI) from Landsat imagery has been frequently used to monitor live vegetation canopy cover and trajectories of forest growth during and after ecosystem disturbances. ${ }^{21,22}$ Advantages of NDVI for the purpose of vegetation monitoring have been cited in its mathematical simplicity and ease of comparability across numerous multispectral remote sensing platforms. ${ }^{22}$

NDVI was computed for this study using Landsat or MODIS image bands as

$$
\mathrm{NDVI}=(\mathrm{NIR}-\mathrm{Red}) /(\mathrm{NIR}+\mathrm{Red}),
$$

where Red is the reflectance from $\sim 0.6$ to $0.7 \mu \mathrm{m}$ and NIR is the near-infrared reflectance from $\sim 0.7$ to $1.1 \mu \mathrm{m}$. NDVI was scaled from 0 to 10,000 (by multiplying by 10,000 and omitting negative, nonvegetation values). Low values of NDVI (near 0 ) indicate barren land cover, whereas high values of NDVI (above 7000) indicate dense canopy vegetation cover. Schiffman ${ }^{23}$ found that summer NDVI values $>5000$ corresponded to a leaf area index (LAI) above 1 and NDVI values $>7000$ corresponded to an LAI above 3 in California montane forests.

The MODIS NDVI product (MOD13Q1) was computed every 16 days since the year 2000 at 250-m spatial resolution and provided in a sinusoidal projection. This MODIS product was quality assessed and filtered for aerosol quantity, cloud cover, shadows, and sun-target-viewing geometry. ${ }^{24}$

\subsection{Ecosystem Delinetations and Statistics}

Six ecosystem boundary areas were delineated on the Brazil Ranch property using $1-\times 1-\mathrm{m}$ resolution NDVI computed from color aerial images, which were obtained and orthorectified in May 2012 by the National Agriculture Imagery Program (NAIP). A circular radius of 100-m length was established around each ecosystem center point (Fig. 1). The Big Sur ecosystems represented were coastal grassland terrace, ridge-top grassland, open shrubland, closed shrubland, ridge-top redwood, and creek-side redwood. Each circular area of 100-m radius covered between 23 and $35(30 \times 30 \mathrm{~m})$ Landsat pixels, depending on the cloud and fogfree period of each year.

A 95\% confidence interval for an NDVI sample mean difference between ecosystem locations was reported as $> \pm 2$ standard errors (SE) ${ }^{25} \mathrm{~A} p<0.05$ value means that the results are significant the $95 \%$ confidence level.

\section{Results}

\subsection{Drought Weather Records}

For the water years (WY; October 1 to September 30) of 2013 and 2014, precipitation in the study region totaled to 69 and $47 \mathrm{~cm}$, respectively, compared to the historical average (1950 to 2016) WY total of $105 \mathrm{~cm}$ rainfall (Fig. 2). Over the three consecutive WYs of 2012 to 2014, only $50 \%$ of long-term annual rainfall was recorded at this Big Sur station location. The slightly higher rainfall total during the WY of 2013 compared with the WY 2014 was attributable to a wetter November to December period. In contrast, total precipitation during the WYs of 2015 and 2016 was 82 and $112 \mathrm{~cm}$, respectively, amounting to $80 \%$ to $100 \%$ of historical annual rainfall. Just prior to the extreme drought period of 2012 to 2014, the WY of 2011 recorded near-average precipitation of $101 \mathrm{~cm}$ at the BSP station. 


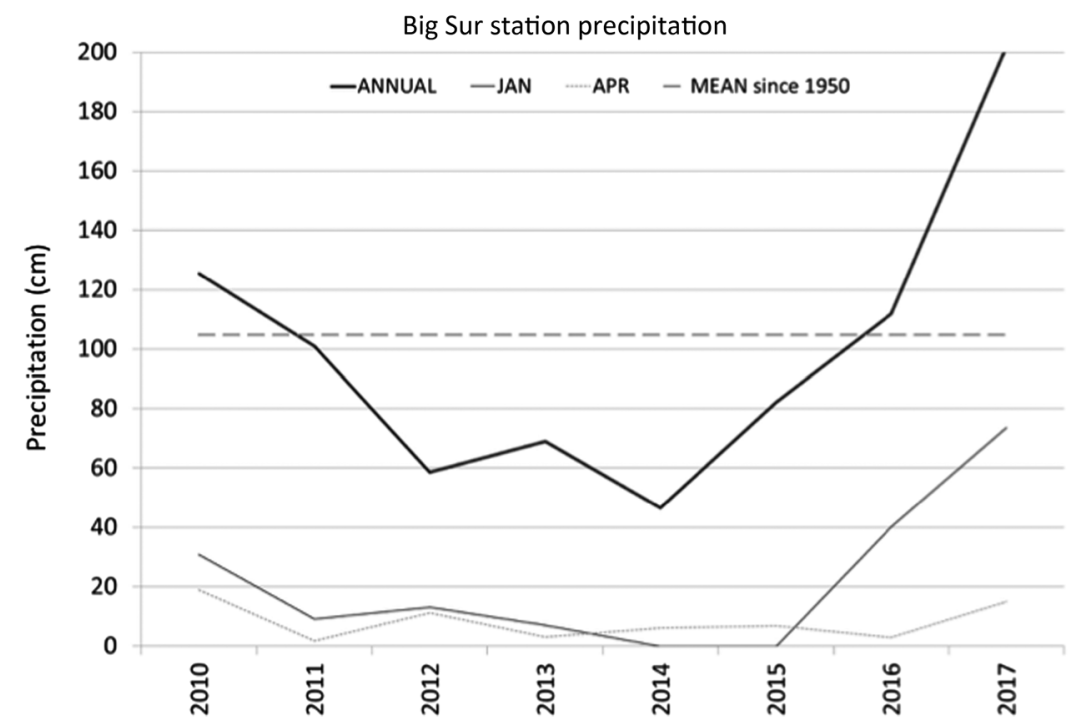

Fig. 2 Big Sur station (BSP) precipitation record from 2010 to 2017.

\subsection{MODIS NDVI: 2000 to 2016}

Comparisons of the long-term (2000 to 2016) NDVI for six ecosystems at the Brazil Ranch showed that the highest annual greenness levels were recorded in the springtime periods of the years of 2005, 2008, 2015, and 2016 (Fig. 3). The lowest annual greenness levels were recorded in the late summer periods of the years 2003, 2007, and 2013.

The presence of coastal low clouds and fog evidently reduced the number of quality-filtered NDVI values at the coastal grassland terrace location, compared to the ridge-top grassland location (Fig. 3). Nonetheless, the peak annual NDVI, recorded in late April to early May of each year, was slightly higher after the year 2007 at the ridge-top grassland compared to the coastal terrace. Peak annual NDVI was nearly identical between open and closed shrubland locations since the year 2000, whereas the lowest greenness level of each year was about 1000 NDVI units lower in the open shrub compared to the closed shrub cover. The NDVI of creek-side redwood forest was notably less variable over each year than NDVI in any of the other ecosystems. The ridge-top redwood forest NDVI was as variable over each year as the open shrubland and grassland locations.

The yearly deviation from the mean of maximum NDVI (computed over all the years since 2000) showed that 2000 to 2003, 2005, and 2016 were above average green cover periods at the majority of ecosystems at Brazil Ranch (Fig. 4). From 2010 to 2014, maximum NDVI levels were below average at the majority of ecosystems. Peak yearly NDVI values were the lowest in 2012 across all six ecosystem locations. Peak NDVI in the two redwood forest ecosystems was the least impacted in 2012, but by 2013, the negative deviation of maximum annual NDVI was more consistent among all ecosystems, except for the coastal terrace grassland.

\subsection{Landsat NDVI: 2010 to 2016}

The 30-m resolution April NDVI, averaged within each 100-m radius circular area for the six ecosystems at Brazil Ranch, showed that creek-side redwood forest greenness was significantly higher $(p<0.05)$ and more stable than all other ecosystem NDVI levels since the year 2011 [Fig. 5(a)]. The average April NDVI of ridge-top redwoods and the closed shrub ecosystem was consistently higher than the open shrub and the two grassland ecosystems, particularly in 2011, 2013, and 2015. The mean April NDVI was lowest across all six ecosystems in 2011 and 2013.

The areas within each ecosystem that showed the lowest NDVI in April were consistently detected within the ridge-top grassland and the open shrubland [Fig. 5(b)] at below 5000 NDVI units, most notably in 2011 and 2013. Despite the relatively low WY precipitation recorded in 

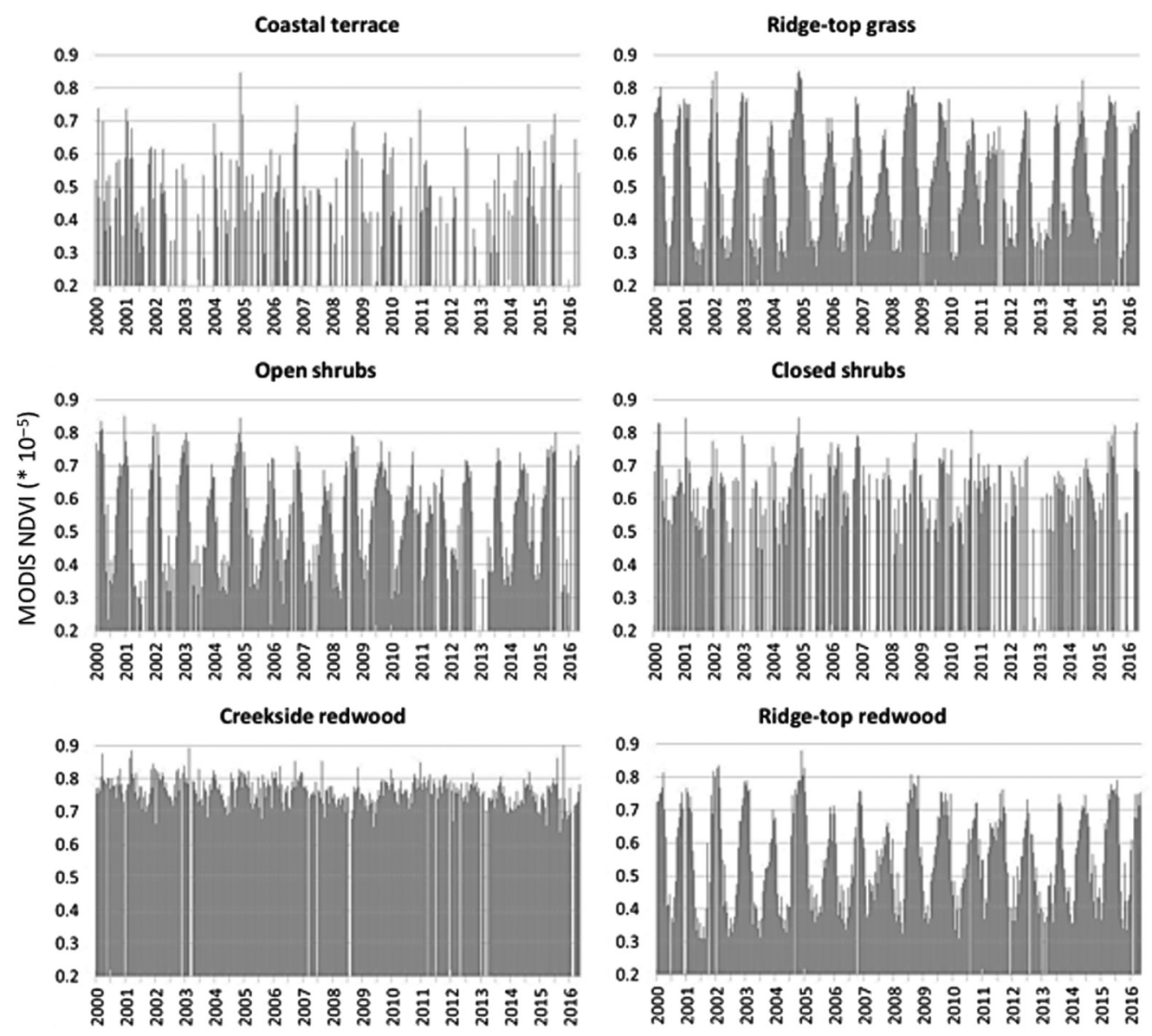

Fig. 3 MODIS time series for 250-m resolution NDVI at six ecosystem center locations shown in Fig. 1.

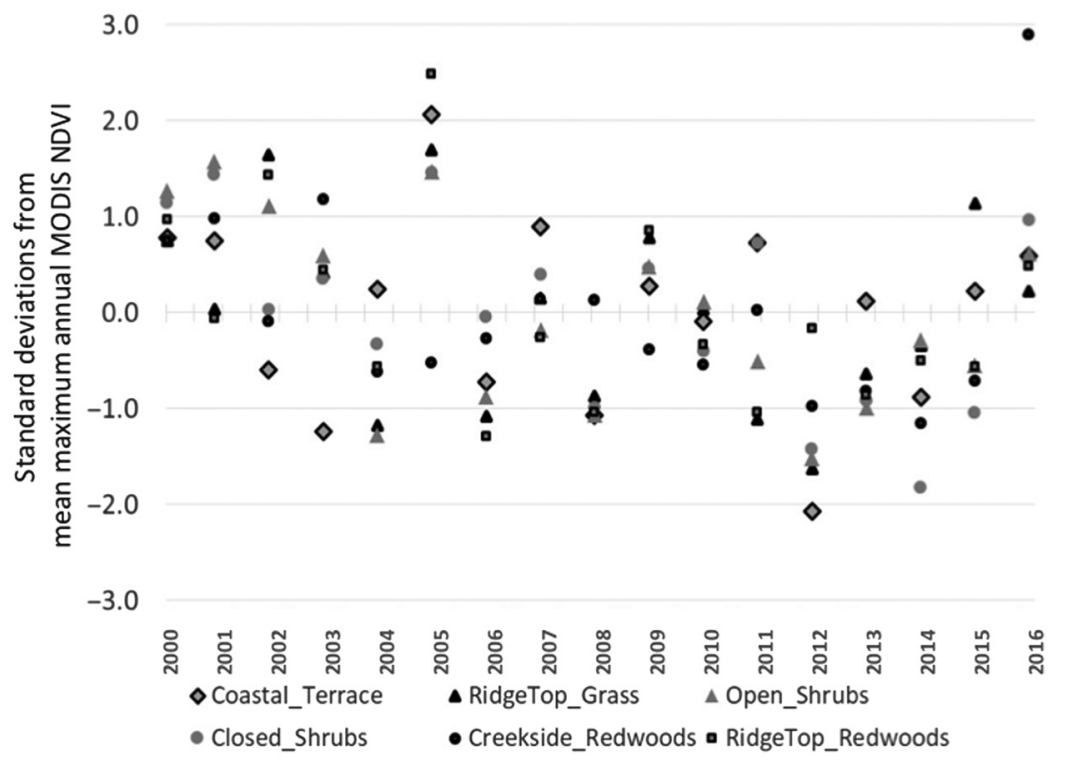

Fig. 4 Yearly standard deviation from the mean of maximum NDVI computed over all the years since 2000 for ecosystem center locations shown in Fig. 1. 
Potter: Differing ecosystem responses of vegetation cover to extreme drought on the Big Sur...

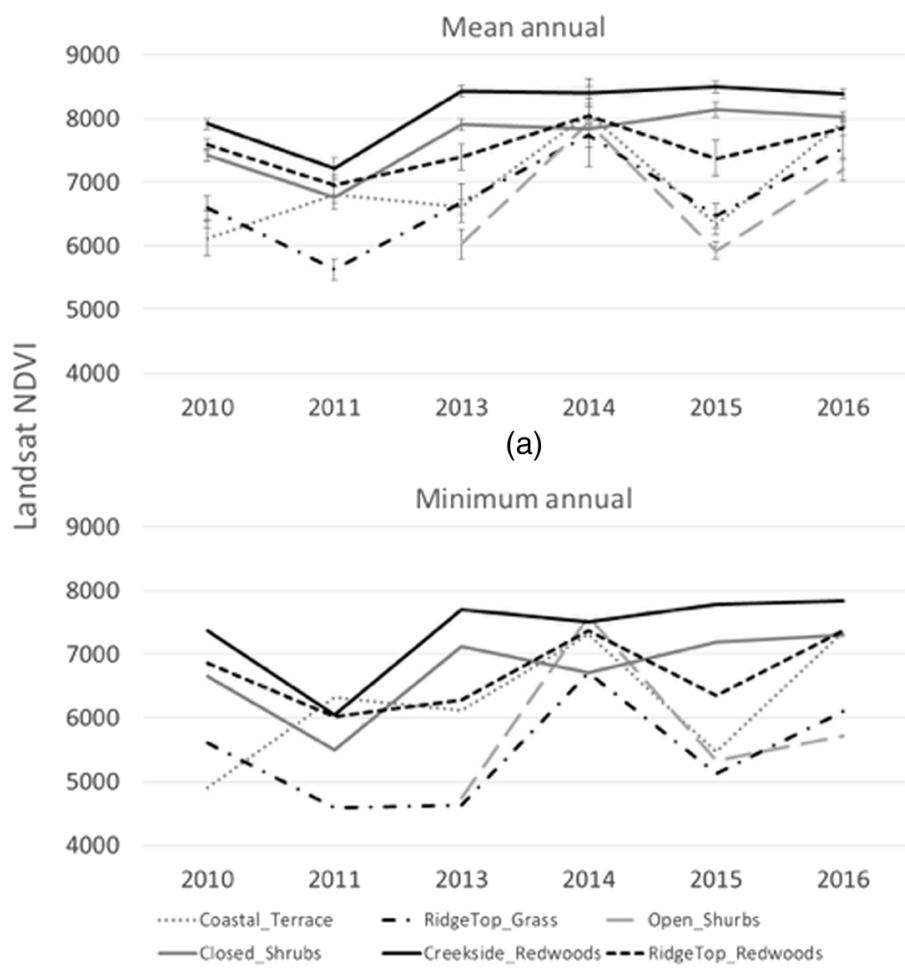

(b)

Fig. 5 Landsat time series for 30-m resolution (a) mean and (b) minimum April NDVI within six ecosystem locations shown in Fig. 1. Error bars show 2 SE of the mean April NDVI.

2014, minimum NDVI detected within the six ecosystem areas was the most consistent, all at between 6000 and 8000 NDVI units, among the years compared. The minimum April NDVI levels within the open shrubland and the ridge-top grassland ecosystems recovered more slowly to predrought levels in 2015 and 2016 than in the other ecosystem areas.

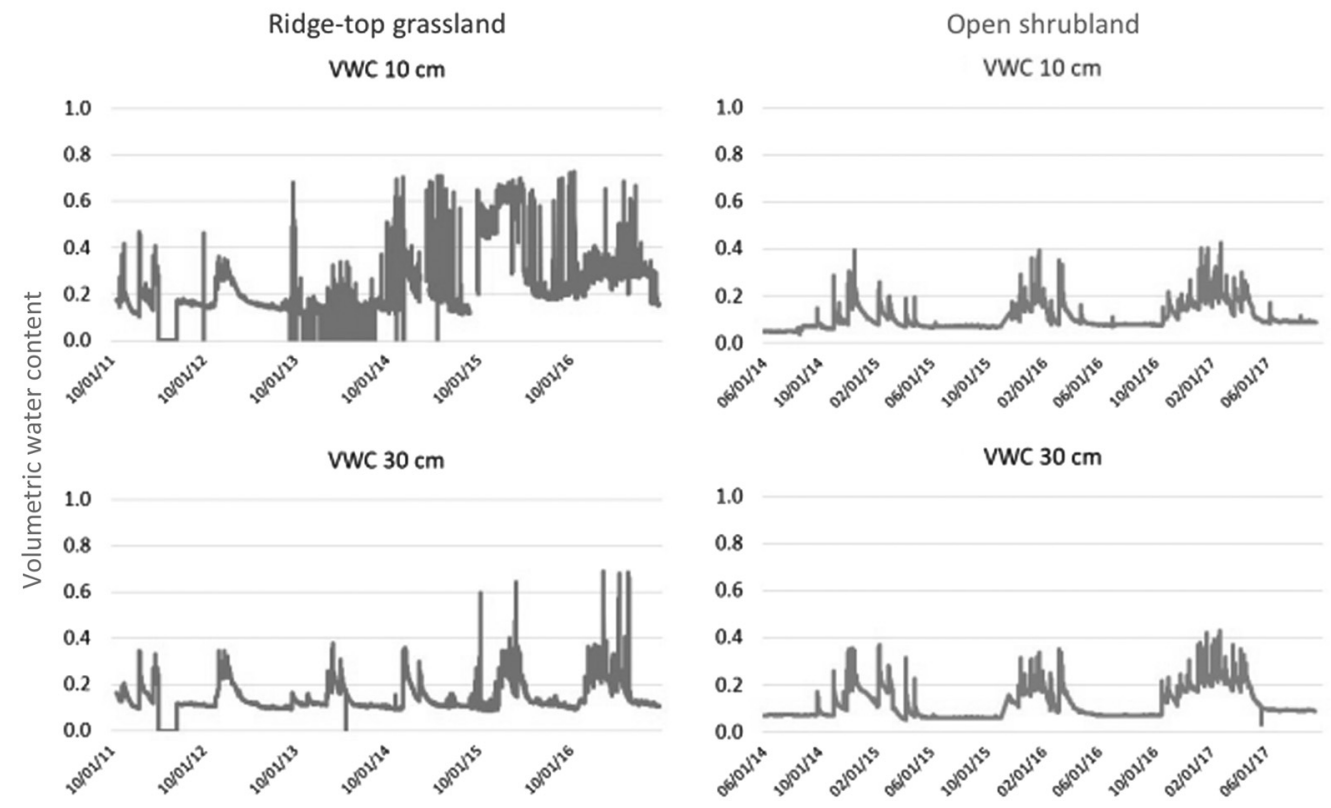

Fig. 6 Plots of hourly soil moisture measured at Brazil Ranch grassland and open shrubland sites. 


\subsection{Soil Moisture Variations}

The record of hourly soil moisture under ridge-top grassland and open shrub cover at the Brazil Ranch from 2011 to mid 2017 (Fig. 6) showed that the dry season months of May to September had the lowest consistent VWC levels at both 10- and 30-cm soil depths during the time series. Grassland soil VWC levels at 30-cm depth remained below 0.4 from 2012 to late 2015, during both dry and wet seasons. The WYs of 2012 and 2013 were the driest and had the most hours recorded below VWC levels of 0.2 of any periods in the grassland time series. Throughout the wet seasons (November to April) of 2015, 2016, and 2017, soil VWC regularly exceeded 0.4 and peaked in the ridge-top grassland site at above $0.6 \mathrm{VWC}$ levels.

\section{Discussion}

It was apparent from visual inspection of NAIP 1-m imagery from May 2012 that evergreen plant cover was sparse within the coastal terrace, open shrub, and ridge-top grassland sites at the Brazil Ranch. In contrast, groups of nearly closed-canopy evergreen plants covered roughly half of the closed shrubland and ridge-top redwood sites, and continuous tree canopy was growing densely over the creek-side redwood site. These differing spatial densities of woody plants among ecosystems corresponded to the observed changes in NDVI over the period of 2010 to 2016 near Big Sur, with the herbaceous-dominated coastal terrace, open shrub, and ridge-top grassland ecosystems declining $30 \%$ in greenness during the extreme drought period, whereas closed shrubland and redwood-dominated sites were relatively unaffected.

Long-term weather station records from the Big Sur coast show that precipitation was about $50 \%$ below historical annual average rainfall over the WYs of 2012 to 2014 . The extreme dry period at the study site lasted for these three consecutive years, rather than only two years, as has been documented over most central regions of the state of California. ${ }^{6}$ Soil moisture measurements at the study site confirmed that plant water shortages persisted from 2012 to late 2015, during both dry and wet seasons at Brazil Ranch.

Peak annual NDVI from the MODIS satellite sensor during the drought of 2012 to 2014 was the lowest of any 3-year period since 2000, and open shrub and grassland ecosystems declined to their lowest levels in the past 17 years during that drought period. The WYs 2005 and 2008 also showed that maximum NDVI was one standard deviation below the long-term mean for open shrub and ridge-top grassland sites, whereas maximum NDVI was closer to the long-term normal for the closed shrub and redwood sites during these relatively dry years. Landsat images (2010 to 2016) from the month of peak NDVI confirmed this as a statistically significant difference in the response of open shrub and grassland ecosystems to the 2012 to 2014 drought compared to the closed shrub and redwood ecosystems at the study sites.

Rainfall is not the only source of moisture for shrub-dominated ecosystems on the Big Sur coast. Over the summer seasons (June to October) of 2014 and 2015 at Brazil Ranch, Potter ${ }^{26,27}$ measured rates of shrub canopy fog interception at levels that helped sustain elevated soil water levels under shrubs and aid woody vegetation survival through extended periods of low rainfall. Summer season totals of 125 and $31 \mathrm{~cm}$ of fog water drip were recorded under open shrub canopies in 2014 and 2015, respectively. If these summer moisture deposition results are representative across the region, then fog water drip to soils under coastal shrub canopies can be equivalent to as much as $50 \%$ of annual average rainfall rates.

From a long-term climate change viewpoint, ${ }^{9}$ reported physiological evidence that coast redwood and most other ecosystems along the Pacific coast may be increasingly drought stressed under a summer climate of reduced fog frequency, higher solar radiation flux, and greater evaporative demand. Carroll et al. ${ }^{28}$ found that correlations between tree-ring chronologies and summer drought indices were statistically significant at 10 California coast redwood forest locations, but the correlations were by far the strongest on the Big Sur coast, where the summer drought index was $46 \%$ coincident with the stem growth chronology. The tree-ring chronologies further showed that stem growth in redwoods on the Central Coast decreased significantly with maximum temperature in April and June.

The patterns of future climate change are uncertain and likely to be complex in Pacific coastal ecosystems. For example, Potter ${ }^{1}$ analyzed 20 years of daily temperature records from the BSP 
location and reported that, even as average monthly maximum temperatures $\left(T_{\max }\right)$ have decreased gradually, the number of extreme warm summer days $\left(T_{\max }>37^{\circ} \mathrm{C}\right)$ has increased by several fold in frequency. Overall patterns in weather station records since the mid 1990s indicated that diurnal temperature ranges are widening on the Big Sur coast, with markedly cooler nighttime temperatures (frequently in the wet winter season) followed by slightly higher than average daytime temperatures, especially during the warm, dry summer season. In summary, climate warming and an increased frequency of extreme weather events, such as the 2012 to 2014 drought, have the potential to tip the balance in favor of or against vulnerable biological resources and the human activities that sometimes require a struggle to prosper in a remote and rugged landscape such as the Big Sur coast.

\section{Conclusions}

Differing densities of woody plants among various plant communities on the Big Sur Pacific coast of central California were closely related to changes in satellite-observed NDVI over the period of 2010 to 2016, with the herbaceous-dominated coastal terrace, open shrub, and ridgetop grassland ecosystems declining 30\% in greenness during the extreme drought period of 2012 to 2014. Landsat images from the month of peak annual NDVI showed a significant loss of green cover in open shrub and grassland ecosystems during the 2012 to 2014 drought, compared to the closed shrubland and redwood-dominated ecosystems that were relatively unaffected during this extreme dry period.

\section{Acknowledgments}

The author is grateful to the U. S. Forest Service, Los Padres National Forest for access to the Brazil Ranch study site.

\section{References}

1. C. Potter, "Understanding climate change on the California Coast: accounting for extreme daily events among long-term trends," Climate 2, 18-27 (2014).

2. C. Hiatt, D. Fernandez, and C. Potter, "Measurements of fog water deposition on the California Central Coast," Atmos. Clim. Sci. 2, 525-531 (2012).

3. P. Henson and D. J. Usner, The Natural History of Big Sur, University of California Press, Berkeley, California (1996).

4. T. H. Ricketts et al., A Conservation Assessment of the Terrestrial Ecoregions of North America, Island Press, Washington, DC (1999).

5. E. Hanak, J. Mount, and C. Chappelle, California's Latest Drought, Public Policy Institute of California, San Francisco, California (2014).

6. R. E. Howitt, Economic Analysis of the 2014 Drought for California Agriculture, 20 p., Center for Watershed Sciences, University of California, Davis, California (2014).

7. F. Shreve, "The vegetation of a coastal mountain range," Ecology 8, 27-44 (1927).

8. J. C. Hickman, Ed., The Jepson Manual: Higher Plants of California, University of California Press, Berkeley, California (1993).

9. J. A. Johnstone and T. E. Dawson, "Climatic context and ecological implications of summer fog decline in the coast redwood region," Proc. Natl. Acad. Sci. U. S. A. 107(10), 4533-4538 (2010).

10. C. Bickford and P. Rich, Vegetation and Flora of the Landels-Hill Big Creek Reserve, 141 p., Environmental Field Program Publication, University of California at Santa Cruz, Santa Cruz, California (1979).

11. M. Borchert, D. Segotta, and M. D. Purser, "Coast redwood ecological types of southern Monterey County,” Gen. Tech. Rep. PSW-107, 27 p., Pacific Southwest Forest and Range Experiment Station, Forest Service, U.S. Department of Agriculture, Berkeley, California (1988). 
12. C. G. Lorimer et al., "Presettlement and modern disturbance regimes in coast redwood forests: implications for the conservation of old-growth stands," For. Ecol. Manage. 258, 1038-1054 (2009).

13. S. P. Norman, "A 500-year record of fire from a humid coast redwood forest," Report to Save-the-Redwoods League, http://www.savetheredwoods.org/research/grant_list.php (2007).

14. M. George et al., Annual Range Forage Production, Publication 8018, University of California, Division of Agriculture and Natural Resources, Oakland, California (2001).

15. J. T. Abatzoglou, K. T. Redmond, and L. M. Edwards, "Classification of regional climate variability in the state of California," J. Appl. Meteorol. Climatol. 48, 1527-1541 (2009).

16. "Cooperative climatological data summaries," Western Regional Climate Center, http://wrcc .dri.edu/climatedata/ (2017).

17. C. Potter, "Microclimate influences on vegetation water availability and net primary production in coastal ecosystems of Central California," Landscape Ecol. 29(4), 677-687 (2014b).

18. "Land processes distributed active archive center (LP DAAC)," USGS/EROS, Sioux Falls, South Dakota, earthexplorer.usgs.gov (2017).

19. J. G. Masek et al., "A Landsat surface reflectance data set for North America, 1990-2000," IEEE Geosci. Remote Sens. Lett. 3, 68-72 (2006).

20. E. Vermote et al., "Preliminary analysis of the performance of the Landsat 8/OLI land surface reflectance product," Remote Sens. Environ. 185, 46-56 (2016).

21. J. W. Wagtendonk and R. R. Root, "The use of multi-temporal Landsat normalized difference vegetation index (NDVI) data for mapping fuel models in Yosemite National Park, USA," Int. J. Remote Sens. 24(8), 1639-1651 (2003).

22. L. Lentile et al., "Remote sensing techniques to assess active fire characteristics and post-fire effects," Int. J. Wildland Fire 15, 319-345 (2006).

23. B. Schiffman, "Estimation of leaf area index (LAI) through the acquisition of ground truth data in Yosemite National Park," in Annual Conf. on American Society for Photogrammetry and Remote Sensing, Portland, Oregon (2008).

24. K. Didan and A. R. Huete, "MODIS vegetation index product series collection 5 change summary," MODIS Land Data Discipline Team, 2006, http://landweb.nascom.nasa.gov/ QA_WWW/forPage/MOD13_VI_C5_Changes_Document_06_28_06.pdf.

25. A. Gelman and J. Hill, Data Analysis Using Regression and Multilevel/Hierarchical Models, Cambridge University Press, New York (2007).

26. C. Potter, "Net primary production and carbon cycling in coast redwood forests of central California," Open J. Ecol. 2, 147-153 (2012).

27. C. Potter, "Measurements of fog water interception by shrubs on the California central coast," J. Coastal Conserv. 20, 315-325 (2016).

28. A. L. Carroll, S. C. Sillett, and R. D. Kramer, "Millennium-scale crossdating and interannual climate sensitivities of standing California redwoods," PLoS One 9(7), e102545 (2014).

Christopher Potter is a biologist who works in the Earth Sciences Division, NASA Ames Research Center, who specializes in the analysis of satellite and aircraft remote sensing images together with sensor measurements on the ground to understand the effects of natural and human changes on the environment. 